We might do better if we concentrated our attention on the successful execution of what ostensibly we attempt. Let us give up arranging meetings at a time when we know, from the circumstances of the case, people cannot and will not attend, and give up also the formality of voting on questions which have been neither read nor circulated. If the popular evening lecture has ceased to be attractive, let us devise some other form of after-dinner appeal with scientific accessories; the Red Lions ought not to lag behind the kinema. If we wish to address an audience, let us address the audience; if we have something to say, let us say it; if we wish to make ourselves heard, let us make ourselves heard or know the reason why; and, finally, if the proceedings are reported, let the Sections make skilled reporting a part of their business. The word recorder seems to have got adrift from its moorings lately. Machinery in motion always has an irresistible attraction; if the meetings of the British Association presented examples of scientific purpose, perfectly managed and scientifically executed, they would be acceptable in many large towns, although the subject-matter might not all of it appeal to the man in the street. It ought not to be forgotten at this particular time that in 1903 Sir Norman Lockyer endeavoured to strengthen the hold of the British Association by keeping its organisation in operation throughout the year, and when the Association declined the suggestion, sought other means of giving expression to his views.

October 3 .

NAPIER Shaw.

If you do not consider the subject of the British Association, which has been so fully discussed in recent issues of NATURE, to be now exhausted, I should like to state briefly how it appears to me.

The Association had at first six "Committees of Sciences." They were in 1835 converted into Sections. The following year another Section was added for Mechanical Science. The Sections continued to be seven only for the next fifty years, when $H$ (or Anthropology) became a separate Section. Botany, Physiology, Educational Science, and Agriculture have since been added, making up the twelve existing Sections.

The Association was not in a hurry, for it was well aware of the practical difficulties arising from a multiplicity of Sections, but these added Seciions have certainly not detracted from its popularity. The Conference of Delegates is another modern development of the work, and keeps interest in that work alive in many parts of the country.

A still more recent extension of the activities of the Association is the Citizens' Lectures, which were very successful at Cardiff. The meeting there was a good one, and would have been much larger but for the exorbitant railway fares. The address of the president, Prof. Herdman, was both brilliant and practical, and will, I hope, be fruitful in the near future.

EDWARD BRABROOK.

October I.

\section{The Examination System.}

Prof. H. E. Armstrong's address on the university problem in London, published in NATURE of September 23 , induces me to make the following remarks with special reference to the examination system in England.

The chief defects are :

(r) Expecting a candidate to remember details necessary for giving a complete answer to an essay question

No. 2658 , VOL. IO6]
(2) Expecting him to answer a lot of questions in three hours.

This has been improved on recently by giving highest honours for five questions out of ten. But, in $\mathrm{my}$ opinion, at most four essay questions in three hours are all that should be expected; and in the case of difficult mathematical or similar questions not more than three.

It is notorious that the best men do not always come out at the top, partly because some hate to be hustled, others think slowly, and others still are not walking encyclopædias even in their own subject.

I know of an institution where the examinations are quite as well managed as in other educational institutions, though I admit the syllabus is so large for the time allowed that there is a good deal of "cram" necessary. As a rule, a student who is good at any subject seldom comes out very high up, whereas others who often have no taste or gitt for a subject are placed at the top Also, there is a student who can come out top of nearly every examination because he is good at examinations.

I suggest the following improvements :

(I) 'i hat students be continuously examined throughout the period of their instruction by weekly or monthly papers and practical work.

(2) That there be fewer questions set in essay or problem papers. Details I have already suggested.

(3) That manuscript note-books of any kind be used by students in all theoretical as well as practical examinations, particularly in scientific subjects.

OXFORD M.A.

\section{An Awkward Unit.}

THERE has lately been introduced on the Daily Weather Report a small map showing barometric tendency. The barometric change from $4 \mathrm{~h}$. to $7 \mathrm{~h}$. is given as "a multiple of the half-millibar, that unit having been found convenient for reading the barograms and adopted for telegraphic reporting " (Meteor. Mag., August, 1920, p. 150).

It is to be regretted that European meteorologists appear to be unaware of the fact that the megadyne or megabar atmosphere was correctly defined by Prof. Theodore Richards in his classic paper on "New Methods of Compressibility," published by the Carnegie Institution in 1903, and in later papers. The bar is a pressure unit expressed in terms of force, and is equal to one dyne per square centimetre. This is the bar of American chemists and physicists, and has been in use at Blue Hill Observatory since I9I4. The term "millibar" which meteorologists hastily adopted in I9I3 appears to us to be a misnomer for "kilobar."

There are many solid arguments in favour of the use of a megabar atmosphere. These will not be repeated here, but it may be pointed out that the expression " multiple of a half-millibar" is awkward. It is so much easier to use the proper definition "500 bar."

Isallobars can then be drawn for any desired value, while it would be rather troublesome to express the same values in fractional parts, such as "one-fifth millibar," meaning a 200-bar change.

Alexander McAdie.

Harvard University, Blue Hill Observatory, Readville, Mass., September 23.

\section{Absorption Spectrum of Hydrogen Chloride.}

THE unexpected satellites which Imes (Astrophysical Journal, November, I919) found beside each line in the $\mathrm{HCl}$ absorption band at $\mathrm{x} \cdot 76 \mu$, and which measurements of his curves show to have an average wave- 